\title{
FERRONES Y CONFLICTOS EN LA CANTABRIA DEL ANTIGUO RÉGIMEN. EN TORNO AL USO Y APROVECHAMIENTO DE LA EXPLOTACIÓN FORESTAL
}

\author{
POR \\ CARMEN CEBALLOS CUERNO
}

Las ferrerías y el abastecimiento de leñas carboneables: dotación y subastas

Cuando el rey, a través del Consejo Supremo de Castilla, otorgaba una Real Cédula y licencia para construir una ferrería concedía, además, el derecho de «dotación» sobre las leñas secas, muertas y rodadas — que restasen después de las destinadas para consumo de los naturales de la zona y de la Corona- de los montes comunales de cada partido en dos leguas en contorno de ella, especificándose en la escritura los nombres de dichos montes y las jurisdicciones a las cuales pertenecían [Ceballos, C.; 194 y ss.]. Este sistema se mantuvo vigente, al menos, hasta 1851 cuando varios ferrones solicitaron a la reina que no «... se inquiete a las fabricas de hierro en el uso y aprovechamiento de los montes que respectivamente estuvieren señalados...» ${ }^{1}$, siendo tal la importancia que para ellos tenía preservar el citado sistema que inten-

${ }^{1}$ Archivo Histórico Provincial de Cantabria (desde ahora A.H.P.C.) «Montes», Leg. 4, n. ${ }^{0} 1$.

Carmen Ceballos Cuerno: Dpto. Historia Moderna y Contempor;anea. Universidad de Cantabria. Santander.

Estudios Geográficos

Tomo LXI, 2000, n. ${ }^{\circ} 240$, julio-septiembre 
taron convertirlo en una verdadera propiedad invocando antiguas costumbres.

La concesión de éste derecho obligaba a los vecinos de las comarcas respectivas a suministrar a los ferrones cada tres años «... a precios $d a$ dos y fijos... las materias elavoradas...», es decir, a proporcionar unas determinadas cargas de leñas con las que hacer carbón y llevarlas a pie de fábrica en el día señalado porque sino «... responderan y pagaran todos los daños ferriales dezima y costas que se le ofreziesen al dicho señor...» ${ }^{2}$. Obligaba, por otro lado, a los ferrones a abonar, por adelantado y en metálico, al regidor de cada pueblo el importe que sumasen tanto las piezas como los carros de montazgo, destinándose la quinta parte respectiva a la Marina Real y a la Conservaduría de Montes.

Sin embargo, esta obligación iba en detrimento de los intereses de los pueblos sujetos a dotación que la consideraban «... como una corruptela apoyada por lo general en el transcurso de los tiempos, como un abuso adquirido a la sombra de la prepotencia de los dueños de las ferrerias y del vasallaje de los pueblos... protegida por los gobernantes, que en ello creian favorecer el desarrollo y la industria fabril, respetada por los Tribunales, y encargada con la obligacion de suministrar a precios dados y fijos a los vecinos de las comarcas respectivas, y a las fabricas nacionales, las materias elavoradas en aquellas...» ${ }^{3}$. Los concejos, alegando que las leñas secas de los montes comunales eran necesarias para el consumo de los hogares, se negaron en repetidas ocasiones a abastecer a las ferrerías de su territorio y ello generó sucesivos enfrentamientos en los tribunales para dirimir quién era el beneficiario ${ }^{4}$, forzando a parar la labranza de algunos ingenios ferriales por falta de combustible, con los pleitos subsiguientes ${ }^{5}$. Era habitual, no obstante, que los ferrones, para procurarse el abasto de leña carboneable, llegasen a acuerdos con los concejos para repoblar y explotar los montes concejiles ${ }^{6}$, acuerdos que al cabo de los años los concejos intentaban rescindir ${ }^{7}$.

\footnotetext{
2 A.H.P.C. «Montes», Leg. 4, n. $^{\circ} 1$.

3 Año de 1840-41. A.H.P.C. «Montes», Leg. 4, n. $^{\circ} 1$.

4 Este fue el caso del pleito entre Luis de Collantes, propietario de la ferrería de La Pendía, y la Junta de San Valentín. A.H.P.C. «Montes», Leg. 4, n. ${ }^{\circ} 2$.

5 Esto ocurrió en 1709 entre el propietario de la Vega del Prado de Selaya y los vecinos de Obregón. A.H.P.C. «Protocolos», Leg. 4.497, folio 50. Para el siglo xIx ver: A.H.P.C. «Montes», Leg. 4.

6 Concejo de Celis, 4 de marzo de 1770. A.H.P.C. «Protocolos», Leg. 2.474, sin foliar.

7 A.H.P.C. «Diversos», Leg. 58, n. ${ }^{\circ} 18$.
} 
A medida que la superficie deforestada aumentaba, sobre todo desde finales del siglo xvIII, las dotaciones de las ferrerías fueron insuficientes pues los montes «... se hallan despoblados y carezen de ynfinidad de arboles para que el termino era a proposito con expecialidad de robles, hayas y alamos a causa de averse cortados los que habia para la Real fabrica de bajeles y otras obras precisas de composturas y fabricas de casas... ${ }^{8}$. No ha de extrañar, por tanto, la concesión de nuevas licencias reales para que las ferrerías ampliasen el territorio de su dotación original ${ }^{9}$, ni que tampoco varias compartieran el contorno de una misma, viéndose obligadas, en este caso, a repartirse tanto las leñas como los pagos de su importe y del montazgo a los pueblos ${ }^{10}$. Ésta situación generó, sin embargo, problemas entre las partes implicadas por los derechos que les correspondieran en esos montes, siendo una de las razones que enfrentó durante casi un siglo a la casa del Rivero y a Juan Fernández de Isla y sus herederos, dueños de las ferrerías de Gibaja y Cereceda respectivamente, por los carbones de Ojebar y Rasines ${ }^{11}$.

Razones económicas, por tanto, movieron las actuaciones de unos y otros pues si los concejos intentaron impedir que los ferrones se abastecieran de las leñas de sus montes inmersos en las dos leguas de las dotaciones - los ingresos obtenidos de su venta serían más elevados si se las vendiesen a otros compradores ${ }^{12}$-, los ferrones no querían perder los derechos de explotación porque representaban una garantía para sus interesés, no sólo porque les aseguraba el abasto de combustible frente a otros postores sino porque les suponía un ahorro al estar obligado el pueblo a venderles las leñas a unos precios fijados y acordados con antelación, precios que incluso podríamos tildar de «políticos».

Pero antes de realizarse la periódica poda y entresaca de las leñas carboneables de los montes comunales se realizaba la subasta pública de las veredas o «suertes» de los montes concejiles. Se podían celebrar,

8 A.H.P.C. «Protocolos», Leg. 2.474, sin foliar.

9 A.H.P.C. «Montes», Leg. 4 , n. ${ }^{\circ}$ 2. Ferrería de La Pendia, 1765 a 1847.

${ }_{10}$ A.H.P.C. «Montes», Leg. 4, n. ${ }^{\circ} 1$, año de 1848.

11 A.H.P.C. «Montes», Leg. 4, n. ${ }^{\circ} 1$.

12 «... El primer metodo presentaria el incoveniente de que se dejaria conocer una grave diferencia entre los pueblos sujetos a dotacion de aquellos que no lo estaban, pues interin que los primeros se verian precisados a dar sus carbones a precios no muy elevados, los segundos los estarian vendiendo a 85 y $102 \mathrm{mrs}$. la arroba que es el que en el dia tienen en la parte oriental de la provincia, desigualdad que haria arrostrar por toda a los carboneros, siendo hasta imposible el contenerles en ese caso. A.H.P.C. «Montes», Leg. 4. 
previa licencia de la autoridad competente sino tenían merced y donación perpetua de todos los montes de su término jurisdiccional, a instancias de los ferrones que preveían una fuerte demanda de combustible, cuando los concejos precisaban de unos ingresos extraordinarios urgentemente..., y se realizaban un año antes de iniciarse el proceso de carbonización y en ellas adquirían los terrenos necesarios para conseguir la cantidad precisa de carbón, en general muy elevada, cantidad que pagaba por adelantado el propietario de la ferrería o su representante ${ }^{13}$.

La vereda destinada a leña carboneable, conocida usualmente por un topónimo, era inspeccionada por peritos agrónomos desde la segunda mitad del siglo XVIII, aunque en décadas anteriores fueran, posiblemente, carboneros especializados en tales labores, personas competentes en suma nombradas a través de las disposiciones legislativas pertinentes ${ }^{14}$ que, acompañados por el ferrón y por unos vecinos en representación del concejo, realizaban «... el señalamiento de las leñas que se pedian, $y$ para presenciar su corta por que se hiciese segun ordenanza...» ${ }^{15}$, calculando el número de carros de carbón que se podrían conseguir y estimando el precio de partida. A partir de los años treinta del siglo XIX, había que solicitar permiso para el acopio de leñas [Ceballos, C.; 200] a la Conservaduría de Montes, permiso que no siempre fue concedido, si bien no fue lo habitual ${ }^{16}$. Solicitaban el nombramiento de un «... perito contramaestre para el señalamiento de las leñas que se pedian..., para que asista a presenciar el aprovechamiento y corta de las mismas... y no se separe de los operarios hasta que se haya verificado el total acopio de acuerdo a la hordenanza», corriendo por cuenta del comprador el pago de sus dietas desde que salía de Santander hasta su regreso a la citada Conservaduría.

${ }_{13}$ El 24 de enero de 1738 la villa de Ampuero se comprometió a entregar 50 cargas de carbón de leña de castaño para el 1 de Agosto en la ferrería de La Iseca del valle de Guriezo, propia de Manuel de Villota Arredondo. A.H.P.C. «Protocolos», Leg. 1.321, folio 82 y ss.

${ }_{14}$ Novisima Recopilacion de las leyes de España. Dividida en XII libros en que se reforma la recopilacion publicada por el señor don Felipe II en el año 1567, reimpresa ultimamente en 1775. Y se incorporan las pragmáticas, cédulas, decretos, ordenes expedidas hasta el de 1804. Mandada formar por Carlos IV. Madrid, 1805-1807, Imprenta Real, título XXIV. De los montes y plantíos, su conservacion y aumento. Leyes I a XXVIII. Biblioteca Menéndez Pelayo de Santander (desde ahora B.M.P.) Sig. 22.190.

${ }^{15}$ A.H.P.C. «Montes», Leg. $4, \mathrm{n} .^{\circ} 1$.

16 A.H.P.C. «Montes», Leg. $4, \mathrm{n}^{\circ}{ }^{1}$. 
Una vez iniciada la puja, los más interesados eran los ferrones de la zona que intentaban hacer valer, en igualdad de condiciones, los derechos adquiridos sobre el territorio de su dotación, pero los problemas fueron contínuos. Los concejos podían negarles el permiso de corta dando lugar a pleitos ${ }^{17} \mathrm{y}$ recurriendo las subastas que se volvían a repetir ${ }^{18}$. Se denunciaba que éstos consumían excesiva cantidad de leñas en el sitio que previamente les habían señalado y se les acusaba «... con su gran poder el introducirse en otras zonas de los montes...» ${ }^{19}$.

Por otra parte, eran los ferrones los que pleiteaban durante años con los concejos por el incumplimiento de los contratos solicitando que les entregasen las cargas estipuladas, pero a menor precio del concertado en concepto de daños ferriales ${ }^{20}$. Otras veces acusaban a los vecinos de introducirse en «sus» veredas y cortaban los árboles ocasionándoles grandes perjuicios, tanto por el retraso en las entregas ${ }^{21}$ como por la pérdida de leña carboneable ${ }^{22}$. En otras denunciaban que las leñas compradas no estaban «... en sazon ni se hallaban criadas...», llegándose a suspender las diligencias de la subasta y teniendo que volver a repetir$\mathrm{se}^{23}$. También decían que las cargas contratadas y abonadas al concejo eran más de las que les habían enviado, llevándole a juicio para que le entregasen el resto de las que faltaban, más los daños y perjuicios que le habían ocasionado ${ }^{24}$.

Los ferrones, además de acudir a las subastas de las veredas comunes de los concejos, podían comprar a los municipios que tuvieran real ejecutoria para vender, como fue el caso del valle de Guriezo, «el abasto de carbones de los montes comunes y concejiles y entresaco de las dehesas reales... ${ }^{25}$ en grandes cantidades, pagando por adelantado $\mathrm{y}$

17 A.H.P.C. «Protocolos», Leg. 1.805, folio 96.

18 A.H.P.C. «Protocolos», Leg. 1.834, folios 65 a 67 . Esta misma estrategia se sigue dando en la actualidad para bajar el precio de la madera siendo los perjudicados en esta ocasión las Juntas vecinales. ARCEO, B.: La actividad agraria en el valle del Pas, Santander, 1984, inédito, p. 63.

${ }_{19}$ Pleito entre los vecinos del valle de Liendo y José de Villota, 11 de enero de 1788. A.H.P.C. «Protocolos», Leg. 1.803, sin foliar.

${ }^{20}$ A.H.P.C. «Protocolos», Leg. 3.568, folio 167 y ss.

${ }^{21}$ A.H.P.C. «Protocolos», Leg. 1.607. folio 36 y ss.

22 A.H.P.C. «Protocolos», Leg. 1.716, folio 165 y ss.

${ }^{23}$ Pleito entre los dueños de las ferrerías del valle de Guriezo y el Común del valle en 1848. A.H.P.C. «Montes», Leg. 4, n. $^{\circ} 5$.

${ }^{24}$ A.H.P.C. «Protocolos», Leg. 3.638, sin foliar.

${ }_{25}$ Este fue el caso del valle de Guriezo que el 8 de Octubre de 1738 le concedió el rey Felipe «... merced y donacion perpetua de todos los montes y tierras valdias y Realengas 
comprometiéndose los miembros del Común a entregar las cargas estipuladas como máximo en dos años ${ }^{26}$. Podían, también, otargar licencia a una persona que les representase en «... quales partes donde combenga...» ${ }^{27}$ para ajustar la compra de las leñas en los montes y reducirlas a carbón, sin importar que estas se encontrasen en otras jurisdicciones. Ello, no obstante, conllevaba varios riesgos cuando se trataba de leñas de montes alejados de las ferrerías y mal comunicados con ellas debido a los arreglos e incluso construcción de nuevos caminos, a las estancias más prolongadas de los carboneros en los montes..., encareciendo los costes de elaboración y transporte y aumentando el peligro de que se hiciera cisco un elevado porcentaje de carbón, riesgos que se pretendían reducir al señalar a esas leñas el perito un precio inferior a las de áreas cercanas a la ferrería, un cierto trato de favor, «... en consideracion a que se halla a distancia de mas de cuatro leguas de la ferreria y a no tener salida por falta de caminos y tener que pagar la construccion dellos...» ${ }^{28}$.

Era habitual que los carboneros ${ }^{29}$ trabajasen en cuadrillas cuando se trataba de grandes cantidades de carbón, cuadrillas que podían estar formadas por unas diez personas. Los contratos se hacían ya desde principios del siglo XVII «... a estilo y fuero de ferreria... que es quintal de fierro por cada quatro cargas de carbon que hacian 112 quintales de fierro...» ${ }^{30} \mathrm{y}$ en ellos constaban todos los datos pre-

comprehendidas dentro de su termino jurisdiccional cediendole como desde luego le cedo el Dominio y propiedad de todo ello, para que lo pueda gozar, vender y enagenar entre sus vecinos para el desempeño de los censos y demas cargas que al presente tienen y en adelante tubieren y aprovecharse de sus pastos, aguas, leñas y arboledas para las fabricas y mantenimiento de sus casas, edificios, ganados, haciendas y demas que hallase conveniente...» A.G.S. (desde ahora A.G.S.) «Dirección General de Rentas» («D.G.R.») 2. ${ }^{a}$ Remesa, Leg. 4.879.

${ }_{26}$ Valle de Guriezo, 6 de junio de 1605. A.H.P.C. «Protocolos», Leg. 1.716, folios 35 y 36 vs.

${ }_{27}$ A.H.P.C. «Protocolos», Leg. 1.607, folio 7 y ss.

${ }^{28}$ Este fue el caso en Agosto de 1849 del propietario de la ferrería de Cades al concederle el Comisario de Montes el abastecimiento en el monte Villaves. A.H.P.C. «Montes», Leg. 4, n. $^{\circ} 2$.

${ }_{29}$ Para el estudio de la elaboración del carbón vegetal y la evolución de su precio y la de la leña carboneable, así como su incidencia en los costes de producción en la segunda mitad del siglo XVIII en las ferrerías de Cereceda y en la de La Iseca del valle de Guriezo (todas de Cantabria) entre 1824 y 1867 ver: CEBALLOS, C.; op. cit., pp. 208 y ss.

30 A.H.P.C. «Protocolos», Legs. 1.711, folio 784 y, Leg. 1.794. Los contratos se hacían entre el ferrón o su representate con un concejo a través del tratante de carbón que hacía las veces de intermediario, bien con la cuadrilla de carboneros (Archivo Familia Martínez 
$\operatorname{cisos}^{31}$, registrándose que «... tenian que estar hechas, cocidas y envasadas para el dia...» ${ }^{32}$ en la ferrería pertinente, aunque también se podían hacer varias entregas cuyo número variaba en función de las cargas contratadas, entregas que puntualmente se señalaban. Si la parte contratada incumplía lo estipulado se comprometía a hacerse cargo de las costas derivadas de la posible parada de la ferrería al no tener combustible, costas denominadas «cargas ferriales».

Estas costas significaban la obligación de fabricar el carbón por parte de los carboneros ya que el ferrón podía enviar a buscarles a su lugar de origen para exigirles el cumplimiento del contrato corriendo ellos con el gasto del viaje y del sueldo de la persona que fuera en su busca, - estimado todo ello en cuatrocientos maravedís diarios-, la devolución íntegra del dinero que se les entregó al hacer la escritura y el valor de los quintales de hierro que se hubieran podido labrar con las cargas de carbón no entregadas, «... al respecto de quarta de fierro por carga de carbon segun el dicho fuero de ferrerias...» ${ }^{33}$ pagando los quintales de fierro al precio usual en la zona y al contado. Podía también obligarles a pagar a otro carbonero el carbón que hubiera tenido que comprar al no serle entregado en su momento ${ }^{34}$.

El ferrón, por su parte, les pagaba lo que correspondiera de la siguiente manera: una cantidad de dinero en metálico entregada en el momento de hacerse el contrato que representaba, más o menos el $80 \%$ del total, y el $20 \%$ restante eran quintales de hierro hasta sumar el resto de la deuda ${ }^{35}$. Pero si se demoraba en el pago tenía que responder «...

Amallo - desde ahora Arch. Fam. M.A.-, 1861), bien oriundos del Reino de Navarra o del Señorío de Vizcaya (A.H.P.C. «Protocolos», Leg. 1.607, folios 35 y ss.) o bien vecinos de la comarca (A.H.P.C. «Protocolos», Leg. 1.711, folio 55), campesinos que habían vendido al ferrón pequeñas cantidades de leña y eran ellos mismos los que hacían el carbón y lo trasladaban a pie de fábrica. Archivo Familia Villota Osborne - desde ahora Arch. Fam. V.O.

${ }^{31}$ Los de los compradores, los de los carboneros y, además de especificar el monte en el cual se iba a fabricar el carbón, se anotaba el número de cargas y su precio además de las medidas que tenían, pues si ello no se indicaba podía dar lugar a pleitos. A.H.P.C. «Protocolos», Leg. 1.871, folio 107 y 159.

${ }^{32}$ La fecha para hacer entrega del carbón solía ser el día de San Miguel, 29 de Septiembre, o en Agosto. Ver, por ejemplo: Contrato fechado en 1612 entre un vecino de Liérganes y la ferrería de Riva Herrera. A.H.P.C. «Protocolos», Leg. 11, folio 67. Contrato de 1604 entre un vecino de Guriezo y la ferrería de La Iseca. A.H.P.C. «Protocolos», Leg. 1.711, folio 65 .

33 A.H.P.C. «Protocolos», Leg. 1.607, folios 35 y ss.

34 A.H.P.C. «Protocolos», Leg. 1.714. folio 37 y ss.

35 A.H.P.C. «Protocolos», Leg. 1.608, folios 112 y ss. 
pena de execuzion y costas de la cobranza. Y no se los dando y pagando como dicho es a el dicho dia y plazo, pasado que sea nos executen nuestras personas y bienes que obligamos en jeneral y en espezial los dichos carbones y fierro...» ${ }^{36}$.

No obstante, podían abonar el importe total de las cargas de carbón de manera diferente y cada una respondía no sólo a sus disponibilidades de capital en el momento, sino a las necesidades de los campesinos. Podían pagar toda la deuda con dinero en metálico y cuando el contrato se cerraba ya constaba que el carbonero había cobrado ${ }^{37}$, podían abonar una parte proporcional de la misma con hierro ${ }^{38} \mathrm{o}$ con especies ${ }^{39}$ y el resto en metálico. Se daba el caso, por otro lado, que a los ferrones les podían adeudar los vecinos una cantidad de dinero procedente de una entrega de maíz, de ganado, de hierro, de un préstamo en metálico... ${ }^{40}$, y al no disponer de liquidez les pagaban con su trabajo como carboneros (elaboración del carbón, traslado a la ferrería, introducción en las carboneras...).

Este tipo de contratos, en cierto modo «personalizados», se adaptaban a la coyuntura del mercado y cuando el notario levantó un mayor número de actas fue en épocas críticas o inmediatamente después de las mismas (crisis de mortalidad, guerras etc.). Para los ferrones representaban una forma de controlar la comunidad campesina al actuar como prestamistas de la misma y se aseguraban el abasto de combustible para la labranza de una forma que no exigiera un desembolso de dinero en metálico del que quizás no dispusieran en un momento concreto. Para los vecinos, ocupados en las tareas del carboneo, además de pagar las deudas que habían contraído con el ferrón ${ }^{41}$, era una manera de acceder a unos ingresos extra-agrarios que les permitiera incrementar

36 A.H.P.C. «Protocolos», Leg. 1.716, folio 90 y ss.

37 Por ejemplo: A.H.P.C. «Protocolos», Leg. 1.711, folios 65, 101, 306, 415, 429, 457 etc

38 A.H.P.C. «Protocolos», Leg. 1.608, folio 112 y ss.

39 En 1607 el ferrón de La Iseca pagó a un vecino de Guriezo 90 cargas de carbón de los montes del valle y se las abonó con 6 ovejas y el resto en dinero. A.H.P.C. «Protocolos», Leg. 1.715, folio 5. En los ajustes de cuentas entre los dueños de La Iseca y los carboneros se señala que les pagaban con maíz, trigo, vino, animales de labor, hierro manufacturado, herramientas etc. Arch. Hnos. V. O., años 1824 a 1861.

40 A.H.P.C. «Protocolos», Leg. 1.877, folios 117 a 118.

41 Relación de las cuentas particulares que llevaba el ferrón de la ferrería de La Iseca, valle de Guriezo, con los carboneros. Años 1824 a 1861. Arch. Hnos. V. O. Andrés de la Riva, propietario de la ferrería del Llanderal de Selaya realizaba prestamos en metálico a vecinos del valle de Penagos, obligándose éstos a devolver la cantidad en vena de Cabarceno y Sobarzo y en carbón vegetal. A.H.P.C. «Protocolos», Leg. 4.450, sin foliar. 
su patrimonio, llegar a tener en propiedad el ganado, conseguir alimentos, poseer hierro ya manufacturado, etc.

\section{Conflictos en torno al uso y aprovechamiento de la explotación forestal}

Las protestas y los conflictos entre la armada y la justicia ordinaria se sucedieron durante varios siglos por la explotación de los montes concejiles en la actual Cantabria. Desde el siglo XvI abasteció de materia prima a los astilleros reales y abrió progresivamente nuevas rutas para acceder a los montes más alejados, ya fuera para servicio de los citados astilleros como para surtir de combustible a las fábricas de Liérganes y La Cavada dando lugar a enfrentamientos con los otros agentes implicados en la explotación del bosque, es decir, con los concejos (mediante las talas y subastas de leña engrosaban sus arcas ${ }^{42}$ ), con los propios vecinos (tenían el derecho de aprovechar los frutos y leñas de los montes gratuitamente y poder llevar a pastar sus ganados ${ }^{43}$ ) y, por último, con los ferrones.

Éstos enfrentamientos están presentes durante el período analizado. Así, en 1582 los vecinos protestaron por la tala de montes y los problemas que les suponía la obligación de acarrear las maderas a los astille$\operatorname{ros}^{44}$. En el siglo XVII las protestas y los conflictos entre la armada y la justicia ordinaria se repitieron por la propiedad y explotación de los montes concejiles, utilizados, como así ocurrió en la zona de Cabuérniga, Cabezón de la Sal y el valle de Carriedo, para extraer madera para los astilleros de otras zonas del reino, caso de Andalucía ${ }^{45}$ : en 1688 se cesó a

42 El almirante Iriarte precisaba talar 2.000 árboles de la Merindad de Trasmiera para construir unos galeones en los astilleros de Guarnizo hacia 1675. Para ello se ordenó a su hijo, el capitán don Millán, que realizase la tala en su nombre. «Precisabánse de momento quinientos, mas al ir el capitán con veinte operarios a continuar la corta, la dura y violenta oposición de los vecinos lo impidió, incluso con armas de fuego. Ordenó entonces al Corregidor la detención del Procurador, don Pedro de Arnuero, y el procesamiento del alcalde ordinario, don Antonio de Acebedo». Bustamante, M.; «Los astilleros de Colindres», Altamira, 1957, pp. 113 y 114.

43 RuIZ, M.; Propiedad de la tierra y estructuras agrarias: el valle del Alfoz de Lloredo en el siglo XVIII, Santander, 1986, inédito, pp. 225 a 227.

44 Biblioteca Municipal de Santander (desde ahora B.M.S.) Ms. 219-3, folio 92.

45 A.H.P.C. «Centro de Estudios Montañeses» (desde ahora «C.E.M.»), Leg. 12, doc. n. ${ }^{\circ} 15$. 
los jueces de plantíos y conservación de montes y su jurisdicción fue absorbida por las justicias ordinarias de los pueblos, revocándose dicha provisión en $1695^{46}$.

Pero la creciente presión sobre el monte y el aumento de la demanda de madera, sobre todo a partir de la segunda mitad del siglo xviII, dio lugar al retroceso de su superficie, preocupante para los mismos coetáneos ${ }^{47}$, y generó problemas entre las partes implicadas en su explotación, denunciando los concejos abusos por parte de las personas encargadas de realizar las cortas para los astilleros reales o elaborar el carbón vegetal para los altos hornos de Liérganes y La Cavada, denuncias que elevaron al rey. Ello se puso de manifiesto, entre otros ${ }^{48}$, en un memorial del concejo de Udías en el que se hacía referencia a talas para la Marina real y para la artillería de La Cavada: «Los oficiales empleados en la operazion ejecutaron a mano armada prisiones, usurparon la Jurisdiccion Real y cometieron otros atropellamientos escandalosos, dirijidos a intimidad los Pueblos que se oponian a la general destruzion de sus montes; pero que no pudieron evitarlo...» [Ruíz, M.; 220]. Tan difícil era la situación que a finales del siglo XVIII y principios del XIX el Ministro de La Cavada envió un informe al Secretario de despacho de Hacienda sobre los «... excesos que se cometen con motivo del establecimiento de varias fabricas de curtidos en los montes de la dotacion...» ${ }^{49}$.

Los pueblos, por estas razones, veían peligrar sus intereses pues los ingresos obtenidos derivados de las talas y subastas de leña incidirían en un aumento de los caudales de propios lo cual a su vez, teóricamente, favorecería a la comunidad. Sin embargo, a largo plazo el

46 B.M.S. Ms. 1.356 .

47 Los contemporáneos eran conscientes de la explotación irracional y sistemática a la que estaban sometidos los montes y G. Bowles reflexionaba sobre ello en 1775: «Vi con lastima muchas montañas despobladas enteramente de sus árboles por los hacheros que las han arrancado sin juicio ni consideracion, no dexando arbol a vida; y así estos terrenos nunca volverán a poblarse...». BOwLES, G.: Introducción a la Historia Natural y a la Geografía física de España, 1775, Imprenta de D. Francisco Manuel de Mena, p. 360.

48 Los regidores y vecinos de Ucieda piden a través del escribano, se les facilite testimonio de las diligencias instruídas contra el absentista José Gándara por los excesos en las cortas de leña para carbones en los montes del concejo. 27 de abril de 1799 . Archivo Diocesano de Santillana del Mar (Cantabria) (desde ahora A.D.S.) «Civil», Leg. 407. Mateo de la Tijera, Subdelagado de los Reales Ingenios y vecino de Trasmiera, mandó cortar leñas del lugar de Viérnoles para 30 carros de carbón. A.D.S. «Civil», Leg. 1.058.

49 Archivo-Museo Don Alvaro de Bazán. Viso del Marqués, Ciudad Real (desde ahora VISO) «Montes», Leg. 4.223. 
mayor beneficiado fue la Corona ya que de dichos ingresos, una parte sustancial de los mismos, iba a parar al tribunal de Marina y a la hacienda regia a través de los impuestos y tenía que invertirse en nuevos plantíos ${ }^{50}$. Si la leña carboneable era adquirida por un ferrón en pública subasta, éste también tenía que pagar un porcentaje del capital obtenido por la venta del hierro labrado a las arcas reales.

Pero el sistema de subastas, como hemos analizado, dió lugar a actuaciones irregulares por parte de los concejos que intentaban revocar anteriores acuerdos con los ferrones para abastecerles de leña de los montes comunes ${ }^{51}$, negativas de los vecinos a surtirles que obligó a parar la labranza en ciertas ferrerías ${ }^{52}$, acusaciones a los peritos de poner precios más bajos de leña por presiones de los ferrones ${ }^{53}$, ilegalidades por parte de los contratistas de madera que antes de iniciar la subasta contrataban con los pueblos el valor de los arboles, convirtiéndose la tasación de los peritos en una mera fórmula para cubrir los requisitos del expediente ya que no había oposición en los remates de las veredas defraudándose, por extensión, al fisco ${ }^{54}$, conducta arbitraria de los ferrones que podaban y cortaban leñas de sitios no convenidos ${ }^{55}$, etc.

Sistema de subastas, no obstante, que permitió a los propios concejiles engrosar sus arcas no sólo con los dividendos obtenidos de tal sistema, sino a través de la venta de los codos cúbicos de madera desti-

${ }^{50}$ Se coincide con Ruíz para el Alfoz de Lloredo. Ruiz, M.; op. cit., p. 212.

51 Este fue el caso del pleito entre Luis de Collantes, propietario de la ferrería de La Pendía en 1782. La Junta de San Valentín intentó impedirle la corta de leñas secas, huecas y rodadas pues decían ser necesarias para sus hogares. La sentencia tuvo lugar el 26 de junio de 1782 y se condenó a los Concejos a que vendiesen a precios justos las leñas sobrantes después de atendidos los hogares de los vecinos a la ferrería. A.H.P.C. «Montes», Leg. 4, n. $^{\circ}$ 2. Otro caso el del concejo de Celis en el siglo xIX con el propietario de la ferrería de Cades. A.H.P.C. «Diversos», Leg. 58, n. ${ }^{\circ} 18$.

${ }_{52}$ Esto ocurrió en 1709 entre el propietario de la Vega del Prado, Selaya, y los vecinos de Obregón. A.H.P.C. «Protocolos», Leg. 4.497, folio 50.

${ }_{53}$ Este fue el caso en Agosto de 1849 del propietario de la ferrería de Cades al concederle el Comisario de Montes el abastecimiento en el monte Villaves. A.H.P.C. «Montes», Leg. 4, n. $^{\circ} 2$.

${ }_{54}$ Al perito de Cades el Gobernador Civil de la provincia de Santander le llamó la atención en 1850 «... por el escesivo valor a que abscienden los remates comparado con las tasaciones...» y se le atribuyen por una a falta de pericia o de celo en el servicio. A.H.P.C. «Montes», Leg. 4, n. $^{\circ} 2$.

${ }^{55}$ El 11 de enero de 1788 varios vecinos del valle de Liendo declararon ante el escribano que «... don Jose de Villota... facilito años pasados con su gran poder el introducirse en el monte propio de Liendo para podar y cortar las leñas en un sitio determinado conviertiendolas en carbon para sus ferrerias...» A.H.P.C. «Protocolos», Leg. 1.803, sin foliar. 
nados a los astilleros reales y de la leña carboneable para las Reales Fábricas. Sin embargo, el destino que en ocasiones se daba a los ingresos del concejo era para pagar las multas impuestas por las ordenanzas reales por no hacer los plantíos, por no cuidar los viveros... ${ }^{56}$ o para cubrir las necesidades derivadas de una época crítica como hemos indicado en páginas anteriores.

Pero los concejos no siempre recibían el dinero de las talas y podas (que redundaba sobre las arcas reales) y, por extensión, sobre los vecinos que, además, veían como un espacio tan rico como el de «sus» montes era explotado sin que ellos vieran el fruto. Por ello, el incumplimiento y las quejas ante el rey debido a las presiones de las leyes tienen su explicación y los viveros y los plantíos reales estaban abocados al fracaso, sobre todo cuando las cargas aumentaban progresivamente para aumentar la extensión de los viveros ${ }^{57}$. Por otro lado, el que las leyes tuvieran que insistir en una serie de puntos cada vez con una mayor insistencia y que las quejas de los concejos y vecinos, que veían lesionados sus intereses, se reiterasen a partir del último cuarto del siglo XVIII, son fiel reflejo de la oposición a las mismas.

La Corona, por su parte, llegaba a acuerdos con ciertas familias de ferrones para que abasteciesen de hierro a la fábrica de anclas de Marrón ${ }^{58}$ y a los altos hornos a cambio del derecho para explotar montes, siendo el más importante el de la familia Ruíz de la Escalera (propietaria de los ingenios de la Junta de Voto - Pontecillas y Riocorto-) que se firmó al fundarse los Altos Hornos y estuvo vigente hasta 1805, convirtiéndose en los primeros asentistas de las reales fábricas. Se comprometían a aprovisionarlas de hierro crudo, siendo el precio del quintal menor que el del mercado. La Corona, en contrapartida, les concedía «... la posesion del uso y aprovechamiento de diferentes montes para

${ }^{56}$ Según Ruíz, además se ordenó rellenar los huecos dejados por las talas, aumentar la superficie dedicada a bosque buscando los sitios más convenientes para plantar árboles nuevos o que se cambiasen los viveros de lugar. RuIz, M.; op. cit., p. 217.

${ }^{57}$ A Udías en 1791 se le ordenó que aumentase la extensión de su vivero a cien varas. Ibidem, p. 220.

${ }^{58}$ Informe del Ministro de la Cavada sobre provision de hierro para la fabrica de Marron. Propone el Ministro se adopte un convenio con los dueños de las Ferrerias del valle de Soba, para que todo el hierro que labrasen, y no bajaría de «... 30 mil quintales, fuese con destino a Marron a los precios regulares, y haciendoles unos repartimientos prudentes de leñas, que con este auxilio y el amparo de aquella conservaduria, se lograria un surtimiento de 3 mil quintales en lugar de los mil que el Ministro de San Sebastian quiere exigir de don Alonso Alvarado...»16 de junio de 1796. VISo, «Montes», Leg. 4.349. 
sus ferrerias, comprehendidos dentro de la dotacion de las cinco leguas de aquel establecimiento [los altos hornos] con que se surtia a este de los hierros necesarios... ${ }^{59}$. Cuando se agotó la leña en los montes de la dotación de La Cavada, era práctica habitual que por Real Orden se les concediera la preferencia del aprovechamiento de leñas muertas, secas y rodadas en otros montes más alejados, ocasionado graves perjuicios a otros ferrones que se vieron obligados a abastecerse de leñas en montes, alejados o no de su dotación original de dos leguas $\mathrm{y}$ dando lugar a pleitos entre ellos ${ }^{60}$.

Uno de los casos más conocidos fue el que enfrentó a Francisco Ruiz de la Escalera con Alonso de Alvarado cuando por Real Orden de 27 de agosto de 1787 se concedió al primero, como hemos señalado asentista de la Corona, la preferencia de aprovechamiento en los montes de la jurisdicción de Ruesga y Soba, obligándose por posteriores reales órdenes al segundo a surtirse de otros montes. Alvarado intentó quitarle a F. Ruiz de la Escalera este derecho ofreciendo a las fábricas reales el hierro de sus ferrerías ${ }^{61}$ a menor precio que dicho F. Ruiz de la Escalera, convirtiéndose en el nuevo asentista hacia 1805.

Por otra parte, cuando por Real Decreto de 30 de agosto de 1760 se revocaron los privilegios a la Casa de Villascastel, propietaria de los altos hornos de Liérganes y La Cavada hasta ese momento, los ferrones locales ya habían presionado con anterioridad para frenar la influencia de dicha casa ${ }^{62}$, que vió como en 1763 su industria pasaba a ser gestionada directamente por la Corona ${ }^{63}$. Las negativas consecuencias que la fundación de los citados altos hornos y su sistema de dotación, en principio

59 VISO, «Montes», Leg. 4.349.

60 Antonio María de Otañes, dice que posee en herencia de sus mayores una porción de monte en el valle de Otañes y rinde la leña cada doce años que se hace para carbón. Cuando había realizado la poda y fue a recoger el fruto, sus operarios fueron requeridos por el regidor del pueblo «... a instancia de los tres dueños particulares de las ferrerias sitas en el propio valle para que de ningun modo entreguen el carbon... so pena de ser detenidos en el camino...» Antonio M. ${ }^{a}$ de Otañes señala que el artículo $2^{\circ}$ de la Nueva Ordenanza se restablece «... a los dueños en el pleno goce de los legitimos derechos de su propiedad...» No quiere que nadie le impida la extracción de leña de su monte. 11 de diciembre. de 1835 . A.H.P.C. «Montes»., Leg. 4 , n. ${ }^{\circ} 1$.

61 Viso, «Montes», Leg. 4.349.

62 Abril de 1754. B.M.S. Ms. 415, folio 214 vs. a 218.

63 En 1760 se intervinieron técnicamente los altos hornos de Liérganes y La Cavada y el 1 de febrero de 1769 se consumó la expropiación. AlCALÁ-ZAmora, J., Historia de una empresa siderúrgica española: los Altos Hornos de Liérganes y La Cavada, 16221834, Santander, 1974, Diputación Provincial de Santander, p. 101. 
de dos leguas alrededor suyo, sobre las ferrerías asentadas en el río Miera en el siglo Xvir ya han sido estudidadas y, en cierto modo, se repiten como consecuencia de la progresiva ampliación del radio de dicha dotación y de las ordenanzas de 1776 que dieron lugar a que los establecimientos ferriales de La Vega en el valle de Cayón y de Las Bárcenas en el valle de Buelna, se vieran obligados a parar la labranza, ocasionando largos pleitos con los propietarios de los mismos que llegaron incluso al Consejo de Guerra en $1777^{64}$. En 1778 los diputados de los montes comprendidos en la dotación de las reales fábricas elevaron al rey unas proposiciones destinadas a la conservación de sus montes ${ }^{65}$, pero el aumento del territorio de la dotación siguió creando problemas a los ferrones y, a finales del siglo xviII, llegaba a la Merindad de Montija perteneciente a la actual provincia de Burgos, con el consiguiente perjuicio para la ferrería instalada en la zona ${ }^{66}$.

La sistemática e irracional explotación a la que estaban sometidos los montes dió lugar, según el director de la misma factoría, a que en 1795 Liérganes cerrase por falta de carbón y en la última década de la centuria ilustrada se buscase con intensidad carbón de piedra para sustituir al vegetal. A finales del siglo XVIII y principios del XIX el sistema de dotaciones de las ferrerías comenzaba a plantear problemas y los ferrones tenían que surtirse de leña de otras jurisdicciones pues los suyos «... se hallan despoblados y carezen de ynfinidad de arboles para que el termino era a proposito con expecialidad de robles, hayas y alamos a causa de averse cortados los que habia para la Real fabrica de bajeles y otras obras precisas de composturas y fabricas de casas...» ${ }^{67}$.

Parte de los agentes que intervinieron en la explotación del monte aparecen claros en ésta referencia, excepto los campesinos quienes veían peligrar el espacio dedicado a la agricultura y pasto para sus ganados al reservarse la Corona las dehesas para viveros y plantíos (intentando mediante los incendios recuperar dicho espacio ${ }^{68}$ ). Pero también plantea el problema de las causas de la deforestación debido, en

${ }^{64}$ A.G.S. «Secretaría de Marina» (desde ahora «S.M.»), Leg. 685. 20 de Marzo de 1777.

${ }^{65}$ A.H.P.C. «Protocolos», Leg. 80, n. ${ }^{\circ} 14$.

66 VISO, «Montes», Leg. 4.349.

${ }^{67}$ A.H.P.C. «Protocolos», Leg. 2.474, sin foliar.

68 En 1797 en el Alfoz de Lloredo se ejecutaban las quemas regularmente «... por particular interes de leñas y pastos en los terminos incendiados...». RuIz, M.; op. cit., p. 222. 
primer lugar, a un aumento de las necesidades de madera por parte de la Marina y de otras industrias [Ceballos, C.; 423 y ss.]; en segundo, porque las labores de repoblación no se hicieron de acuerdo a las ordenanzas; en tercero, porque el incremento de la producción de hierro precisaba, en contrapartida, otro de la demanda de combustible (tanto por parte de las ferrerías como de las fábricas reales) por lo que las dotaciones originales fueron insuficientes. Pero, probablemente, la combinación de las tres posibilidades sea la hipótesis más probable, a la que añadimos la disminución del intervalo de podas y talas y «... por la mala calidad del terreno aunque se ha hecho plantio de robles y hayas desde que se espidio la orden de S.M. [se refiere a la ordenanza de 1748 ]... son muy pocos los que han arraigado» 69 ... Por otra parte, la Corona, tal era su apremiante necesidad de madera se vio en la obligación de importar madera de Europa («... roble blanco de Prusia, de los montes de Rusia madera para perchas, roble y álamo negro de Italia, de la Albania turca está el rey dudando pues es una zona poco segura, de Francia, roble corona para entablar fragatas de Polonia, pino del Báltico, de Riga maderas cuadradas de pino, de San Peterburgo pino cuadrado para tablonería...» ${ }^{70}$ ) y de Indias (intendencias del Cuzco y La Habana) ${ }^{71}$ para sus astilleros desde mediados del siglo XVIII ${ }^{72}$.

A principios del siglo XIX, las dificultades de la crisis general de la economía y de las instituciones del Antiguo Régimen, las guerras y el descontrol del país, la contínua demanda tanto de madera por parte de la ciudad de Santander como de productos cárnicos y lácteos de la población que dio lugar a un aumento de la cabaña ganadera y a la necesidad de una mayor superficie de pastos para alimentarla... todo ello intensificó el proceso de pratificación en la región, proceso que fue de tal magnitud en el valle de Guriezo que la superficie de las tierras dedicadas a pasto entre 1752 y 1863 se multiplicó unas dieciocho veces [Ceballos,

69 Lugar de Aloños, valle de Carriedo. A.H.P.C. «Ensenada», Leg. Respuesta General n. ${ }^{\circ}$ 7, 1752. No obstante, a mediados del siglo XvII, era habitual que los lugares respondieran que el único plantío exististente era el de los árboles frutales y alrededor de un $20 \%$ de los pueblos, la mayoría costeros, decía que no había plantío alguno de árboles.

70 Viso, «Arsenales», Leg. 3.785.

71 De las Indias llegaron a España, al menos desde 1735, maderas duras como caoba, guayacán... A.G.S. «S. M.», Leg. 305.

72 Viso, «Arsenales», Leg. 4.356, 3.762, 3.770. Propuesta de provisión de madera de roble de la Albania turca para Cartagena, 1790. VISO, «Arsenales», Leg. 3.795. Acopio de remos y cobre en planchas de Trieste para provisión de los Departamentos, 23-XII-1794 a 19VIII-1795. Viso, «Arsenales», Leg. 3.814. Ceballos, C.; op. cit., pp. 423 y 424. 
C.; 424], y «propició» que las cortas ilegales se realizasen asiduamente. Ello favoreció, en cierto modo, a los ferrones porque veían en «...la piratería de la madera...» una posibilidad de acceder al combustible pero, por otro lado, les perjudicó al tener que comprarlo más caro que en las subastas. Los montes públicos fueron ocupados por los vecinos ante el beneplácito y, en ocasiones, colaboración de los responsables de velar por su conservación como fue el caso del alcalde ordinario de la Junta de Ribamontán para el que se pedía pena de cárcel en $1802^{73}$. Estos problemas se traslucían en las contínuas «advertencias» de los comisarios de las Reales Fábricas a los que incumplen la ley ${ }^{74} \mathrm{y}$ en las dificultades de los vecinos para encontrar leña, teniendo que realizar onerosos desembolsos que agravarían, aún más, la situación económica de las familias que se verían obligadas a trasladarse a otras zonas ${ }^{75}$.

A partir de 1810-1815 los pueblos y sus justicias respectivas tuvieron «licencia indirecta» para conceder permiso de corta que potenció el ya tradicional tráfico ilegal de madera y carbones que, como ya hemos señalado, benefició a los ferrones pero aumentó el precio del carro de carbón: «... sucedera que el costo que se paga por cada carro... de los proximos montes, por precio de 40 reales de vellon, ascendera a 140 reales hasta 150 ...» Los traficantes eludían las prohibiciones escudándose en la posesión de licencias expedidas por los Regidores ${ }^{76}$. La «respuesta» por parte de los campesinos ${ }^{77}$ —obligados a solicitar li-

${ }^{73}$ El ministro de La Cavada dirige un testimonio en el que acredita los excesos cometidos por el Alcalde ordinario de la Junta de Ribamontan en una corta de árboles realizada con su permiso, y sin conocimiento ni autorización del tribunal de La Cavada. Se pide prisión para el alcalde de 15 a 20 en la carcel de las Reales Fábricas o en el castillo de Santander. 3 de Noviembre de 1802. VISO, «Montes», Leg. 4.350.

745 de agosto de 1816. A.H.P.C. «Montes», Leg. 12; 6 de abril de 1825. A.H.P.C. «Sautuola», Leg. 56, n. $^{\circ} 22 ; 14$ de abril de 1826. A.H.P.C. «Sautuola», Leg. 56, n. ${ }^{\circ} 119 ; 8$ de mayo de 1827. A.H.P.C. «Sautuola», Leg. 56 , n. ${ }^{\circ} 135 ; 27$ de Febrero de 1829. A.H.P.C. «Sautuola», Leg. 56 y Bando sobre incendios del 4 de diciembre de 1824. A.H.P.C. «Sautuola», Leg. 62, n. ${ }^{\circ} 47$.

${ }^{75}$ Un vecino de San Mamés, Junta de Voto, el 13 de Septiembre de 1807, informa que se tuvo que trasladar con su familia al lugar de Colindres: dice que no tenía leña «para emparrar sus viñas, pues no hay montes en el pueblo ni en sus inmediaciones; y por lo mismo tiene que traerlas de largas distancias a costa de crecidos desenvolsos...» Pide que se le permita sacar madera para hacer las guías de sus montes de San Mamés que están dentro de la dotación de la Cavada. VISO, «Montes», Leg. 4.350.

${ }^{76}$ A.H.P.C. «Montes», Leg. 4, n. $^{\circ} 1$.

77 Una vez superada la crisis de los primeros años del siglo xIX, la población de la provincia aumentó sus efectivos (LANZA, R.; La población y el crecimiento económico de Cantabria en el Antiguo Régimen, Madrid, 1991, U.A.M.-Universidad de Cantabria, pp. 135 y 
cencia para explotar ciertas especies y a utilizar otras de menor calidad y menos adecuadas para el uso al cual les destinaban tradicionalmente $^{78}$ - y de los propietarios de las ferrerías a las leyes no se hizo esperar: los primeros fueron los «responsables» de la proliferación de incendios ${ }^{79}$ (práctica, por otra parte, que ya utilizaban en épocas anteriores ${ }^{80}$ ) en los montes reales que fueron cada vez más numerosos $\mathrm{y}$ hubo que volver a poner en activo antiguas ordenanzas ${ }^{81}$ y dictar una nueva normativa específica para intentar atajarles ${ }^{82}$, se organizaron cuadrillas que aprovechando la noche realizaban cortas ilegales, el contrabando de madera y de carbón por los puertos, sobre todo el de Santoña y Santander ${ }^{83}$, se convirtió en una actividad muy lucrativa practicado, al menos desde la centuria anterior, y las subastas de las ve-

ss.), la ciudad de Santander creció y necesitó mayores cantidades de madera, se incrementaron las cosechas y los excedentes cerealeros en Castilla así como la demanda de aperos de labranza, la progresiva proletarización del campesinado...

${ }^{78}$ En 1790 a los vecinos del Alfoz de Lloredo se les «... manda que usen sobeos de cuero, avellano o sauce, pero no de madera de cajigas, que cortan por el pie, ya que va en detrimento de la conservación de los montes...». RuIz, M.; op. cit., p. 221. Santander, 12 de octubre de 1809. Providencia del Gobernador político-militar y subdelegado de todas las Rentas de la ciudad de Santander y su Provincia don Santiago Arias, dada «... la escasez de madera de construccion, carbones y leñas para los hogares, hornos, y otros urgentes usos...». Se prohibe que se corten por el pie cualquier tipo de árboles, y si es para construcción ha de tener licencia superior... A.H.P.C. «Sautuola», Leg. 21, n. ${ }^{\circ} 8$.

${ }^{79}$ El monte de la Coterilla y Medianedo, del pueblo de Pámanes, se quemó como de 200 carros de monte argoma y cría de roble. Se hace averiguación por los daños causados y nadie del pueblo sabe nada. Según los peritos, los daños ascienden a 400 rs. 7 de Noviembre de 1859. El 10 de Diciembre de 1859, el Gobernador civil dice que el incendio no fue producto de una casualidad, sino intencionado. Hay dos inculpados, pero el testigo no les reconoció por lo cual no pueden condenarles. A.H.P.C. «Diversos», Leg. 24, n. ${ }^{\circ} 1$.

${ }^{80}$ Despacho y Edicto del Juez Conservador de Montes de las Reales Fabricas de Artilleria de La Cavada, haciendo saber que mientras las actuales circunstancias del Estado perduren, se condenará irremisiblemente a «... los Reales Baxeles a todo el que cometa incendio de Montes, destrozo de arboles etc...» y se nombra algunos vecinos ya condenados y la fecha del fallo del juzgado. La Cavada, 26 de mayo de 1794. A.H.P.C. «Sautuola», Leg. 54, n. ${ }^{\circ} 10$.

81 Teodoro de Argumosa, Comandante militar de este Tercio Naval y privativo de esta Provincia, Juez de Reales Plantios de Montes Comunes, hace saber a los Corregidores, Alcaldes mayores, sus Tenientes o cualquier persona que ejerza jurisdicción en esta zona que el Capitán del Departamento de El Ferrol ha mandado que vuelva a regir la ordenanza de 1748 , pues el rey quiere poner «... pronto remedio a los males que esta sufriendo el estado, por las escandalosas talas, incendios y destrozos de toda especie que experimentan los Montes del Reyno, y amenazan su total ruina...» Santander, 17 de febrero de 1815. A.H.P.C. «Sautuola», Leg. 55, n. $^{\circ} 228$.

${ }^{82}$ Santander, 4 de diciembre de 1824. Bando sobre incendios. A.H.P.C. «Sautuola», Leg. 62, n. $^{\circ} 47$.

${ }^{83}$ VISO, «Montes», Leg. 4.350. 
redas carboneables de los comunes, como ya hemos constatado, estaban plagadas de irregularidades desde hacía tiempo...

Pero los pleitos por el acopio de leñas más conocidos fueron los que enfrentaron al ayuntamiento del valle de Guriezo con los Villota y Entrambasaguas, propietarios de la ferrería de La Iseca y del Calce de dicho valle respectivamente. Se remontan al siglo xvII pero se intensificaron progresivamente y se recrudecieron en el siglo XIX ${ }^{84}$, acusándose unos y otros de incumplir los acuerdos y de dañar los intereses de la parte contraria ${ }^{85}$. En 1848 los ferrones denunciaron al ayuntamiento por vender leñas que no estaban criadas ni de ser el número de cargas que había acordado con ellos ${ }^{86}$ : la respuesta de la alcaldía era la celebración de nuevas subastas, lo cual perjudicaba a los citados ferrones ${ }^{87}$, situación que se repitió, al menos, hasta la década de los setenta en el valle de Guriezo $^{88}$ y en otras zonas de la región afectadas por el mismo problema.

Asistimos, por tanto, al fracaso de la administración en su propósito de mantener la superficie forestal en beneficio propio ${ }^{89}$. Planteó su política como un esfuerzo por repoblar y conservar los bosques, pero la contínua y cada vez más creciente demanda de madera (además de la reducción del período de podas y de talas, que se producen a un ritmo más rápido que el tiempo que se precisa para regenerar un bosque, un pro-

${ }^{84}$ Febrero de 1827. Villota y Francisco de Santa Cruz, en representación de su padre Ramón, arrendatario de la ferrería del Arenal de Guriezo, dicen percibir en el corriente año para sus ferrerías 5.000 cargas de carbón o leñas capaces de producir las 5.000 cargas. Ganaron pleito para su acopio al ayuntamiento en el Real Consejo Supremo de Guerra. Se les dió varios terrenos que contienen leña de avellano, espino, algo carrasco en encina y otras leñas muertas, que uno de ellos podría producir 2.800 cargas, y se complementarían con otros terrenos. Se pagaría la leña a $13 \mathrm{mrs}$. Por último se concede permiso a los ferrones a utilizar la leña capaz de producir 5.700 cargas de carbón, unos 2.885 rs. A.H.P.C. «Protocolos», Leg. 1.834, folio 11 a 13 vs.

${ }^{85}$ En 1830 los vecinos del barrio del Llanderal de Guriezo se han reunido con los dueños de las ferrerías ante el juez pues los primeros «... han cortado las leñas del monte del sitio de Baula parda y sus inmediaciones sin permitir que se carboneen para ferrerias, fraguas ni otros usos que el de el aprovechamiento de los ogares...». Archivo Municipal de Guriezo (desde ahora A.M.G.) «Procedimiento Civil», documento n. ${ }^{\circ} 205$. Por otro lado, el alcalde constitucional de Guriezo escribe a F. de Villota y a C. de Entrambasaguas, que acudieron en 1838 a comprar 15.387 cargas de leña para carbón que habían de sacarse de los montes de Agüera y Remendón, propios del valle. A.H.P.C. «Montes», Leg. 4, n. ${ }^{\circ} 2$.

${ }^{86}$ Abril de 1849. A.H.P.C. «Montes», Leg. 4.

87 A.H.P.C. «Montes», Leg. $4, \mathrm{n}^{\circ}{ }^{\circ}$.

88 A.H.P.C. «Montes», Leg. 8, n. $^{\circ} 1$.

89 Fue, por ejemplo, el 22 de junio de 1776 cuando Juan Machón y José Gil de la Torre, asentistas de herrajes, propusieron el establecimiento en las cercanías de Santoña de una fábrica de herrajes, pero el rey denegó el permiso. A.G.S. «S. M.», Leg. 813. 
ceso a largo plazo...) y el ineficaz control de las mismas personas encargadas de velar por los montes así como los intereses (privados, públicos, comunales, etc.) que giraron en torno a ellos, hizo imposible mantener la masa forestal.

La decadencia del bosque, resultado del uso incontrolado y abusivo del mismo, tuvo consecuencias muy claras para las comunidades y los ferrones. Unos temían por la suerte de un recurso, el monte, que, además de complementar su dieta alimenticia, les reportaba unas utilidades tanto materiales como pecuniarias. Temían, también, por el ahorro que les suponía adquirir los aperos y demás utensilios de hierro a un precio menor que en el mercado, y por unos ingresos que variaban según el papel que desempeñaran en la producción del hierro. Otros, los ferrones, temían ver lesionado su «derecho» de dotación de madera carboneable, es decir, su abasto de combustible y la Corona veía peligrar el funcionamiento de sus industrias (astilleros y altos hornos) por lo que intentó monopolizar y acaparar la riqueza forestal de la región y potenció el plantío de unas especies de árboles frente a otras y condicionó, en cierto modo, la explotación que de los mismos hacía la comunidad campesina y los ferrones.

RESUMEN: La riqueza y las posibilidades de aprovechamiento del bosque en el Antiguo Régimen eran inmensas, siendo precisamente el enorme potencial de su uso lo que generó graves conflictos entre las partes implicadas en su explotaci;on. Conflictos en los que se vieron implicados, de forma directa, no sólo los propietarios o administradores de las ferrer;ias, sino los Concejos, los vecinos y la Corona que intent;o, a través de una serie de medidas legislativas, monopolizar su explotación y hacerse con su propiedad y llegó incluso a frenar la construcción de ingenios que representasen una competencia para el abasto de sus industrias. Sin embargo la madera, recurso energético renovable, no se regeneró al mismo ritmo que el incremento de la demanda y ello originó el retroceso de la superficie forestal y, por extensión, la posibilidad de que los ferrones tuvieran problemas para conseguir combustible.

PALABRAS Clave: Ferrer;ias, Aprovechamiento forestal, Bosque, Carbón vegetal, Conflictos.

ABSTRACT: In the Old Regime forest natural resources and its possibilities of use were of immense importance. This great use potential caused conflicts among the participants involved in its exploitation. These disputes affected directly not only to the Iron Works owners or administrators but to the Concils, neighbours and the Crown that through legal channels tried to monopolize its exploitation and obtain its property. They even tried to curb building devices that were an obstacle for their industry. However, wood, renewable energetic resource did not regenerate at the same rate as the increase 
in its demand. For this reason, the forest surface suffered a serious setback and at the same time, getting fuel for the «ferrones» became a difficult aim.

KEY wORDS: Iron Works, Forest exploitation, Forest, Charcoal, Conflicts.

RÉSUMÉ: La richesse et les possibilités d'utilisation de la forêt dans l'Ancien Régime, étaient immenses, étant précisément l'énorme potentiel de son usage ce qu'a généré de graves conflits parmi les parties impliquées dans son explotation. Des conflits où étaient impliqués, de façon directe, non seulement les propriétaires ou les administrateurs des forges, mais les Communes, les voisins et même la Couronne, laquelle a essayé, à travers une série de dispositions legislatives de monopoliser son explotation et de devenir propriétarie arrivant même à freiner la construction des engins qui représentaient une concurrence pour l'approvisionnement de ses industries. Cependant le bois, ressource énergétique renouvelable ne s'est pas régénéré au rythme de l'accroissement de la demande et cela a occasionné la régression de la surface forestière et, par extension, la possibilité des «ferrones» d'avoir des problèmes pour obtenir du combustible.

MоTS CLEF: Forges, Utilisation de la forêt, Forêt, Charbon de bois, Conflics. 